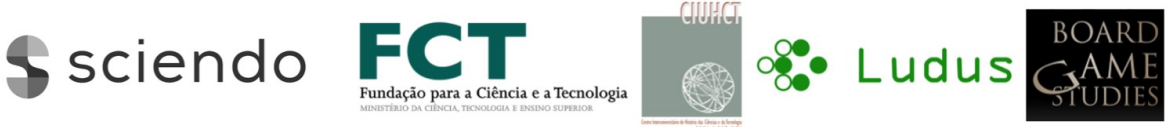

\section{MisconcEPTIONS IN THE HistoRy OF MANCALA GAMES: ANTIQUITY AND UBIQUITY}

\author{
Alex de Voogt \\ Drew University
}

\begin{abstract}
Mancala games are commonly defined by the appearance of the boards and mode of moving the pieces. The similarities have led to the belief that most mancala games are historically related or that they may be identified by appearances alone. Their ubiquity in Africa and their occurrence as graffiti boards on ancient monuments has created speculation about their antiquity. To this date their ancient status cannot be confirmed by archaeological or historical evidence. Based on today's understanding, mancala games are of distinct kinds with separate histories while their antiquity goes back hundreds of years but not yet thousands.

Mancala games have been instrumental in showing that so-called complex societies and the presence of board games are not necessarily related. By extension, state formation and the development of board games should not be connected based on the evidence of contemporary mancala gaming practices.
\end{abstract}

Mancala games are a group of games of which several hundreds have been described in the literature (e.g., Murray 1952, Deledicq \& Popova 1977). Their origins and distribution have captured the imagination since they were first called the national game of Africa by Stewart Culin (1894). In the following, the status of mancala games as a group that shares a common history is questioned. A discussion of the evidence for the antiquity of mancala games further challenges general assumptions about mancala. The specific case of mancala games attested in Egypt illustrates the possible confusion. Instead of speculating on their history, the ubiquity of mancala games is shown to be particularly useful to dispel a long-standing belief that so-called complex societies are more likely to play strategic games.

Board Game Studies Journal Volume 15, Issue 1, pp. 1-12 DOI: $10.2478 /$ bgs-2021-0001 


\section{Mancala games as a family}

The resemblance of mancala game boards to each other in disparate parts of the world have grouped them together in scholarly and popular overviews of board games. Murray (1952) distinguished two-row and fourrow mancala games. Even though all his other groups of games were named after anthropological pursuits, such as war and hunting, mancala games were not associated with a particular human activity. In some communities, they use seeds that are 'sown', in others they are shells played on boards in the shape of fish, and pastoralist societies are known to call the counters 'cows' and use 'trade' as the overarching theme. In short, mancala games consist of an abstract set of holes and counters on which multiple local meaning-making activities can be projected (see also Danilovic \& de Voogt 2020).

While it is plausible that the similarity of mancala games around the world is not coincidental, the amount of historical links necessary to explain such a world-wide distribution is overwhelming. The understanding of such historical links is limited to just a few. For instance, the link between West Africa and the Caribbean by way of the Trans-Atlantic slave trade has explained the almost identical game board configurations and playing rules found in both regions (Herskovits 1932; Murray 1952). Similarly, the Swahili trade routes explain the distribution of bao, a four-row mancala game, which is found with the same particularly detailed rule sets from Kenya (Townshend 1986) to Madagascar (de Voogt 1999) and further inland. In Asia, similar connections have been made for so-called pussakanawa games identified by Eagle (1995) as well as between dakon, ohvalhu and congka games (Donkers et al. 2002). But in all these cases, identical game rules were the basis for making a historical connection rather than a similarity in overall appearance or a minor similarity in rules.

Perhaps the problem of linking all mancala games historically is best illustrated with an analogous example. If we suggest a historical link between all board games in which a playing piece jumps over another piece and where the board consists of a set of fields, then, although not strictly historically impossible, too much historical evidence is required to make such a broad and ambitious hypothesis even likely.

Instead, mancala games and most other board games are best studied using the concept of "cultural traits" (Lyman \& O'Brian 2003:245). Such a

Board Game Studies Journal Volume 15, Issue 1, pp. 1-12 DOI: $10.2478 /$ bgs-2021-0001 
trait consists of a specific practice, specific rule sets as well as a particular appearance. The more specific, the stronger is the case for a historical connection. Without much specificity, other explanations, such as the possibility of independent inventions, become similarly likely.

\section{Earliest evidence of mancala}

The first known evidence of mancala is complicated by the limitations of the archaeological record. In the case of most board games, the record only affords us game boards, dice and game pieces but rarely playing practices and hardly ever any rule sets. The presence of two rows of depressions is not particularly diagnostic as rows of holes may fulfill other functions. This is in contrast with several other game boards that have highly characteristic configurations so that even fragments may be diagnostic, e.g., the game of 58 holes, or that are limited to a fixed set of fields, e.g., the game of five lines (see Crist et al. 2016 for an overview).

An often-quoted earliest attestation of mancala was presented by Pankhurst $(1971,1982)$ with boards excavated in Eritrea and dating to the sixth and seventh centuries CE. Although it is possible these are game

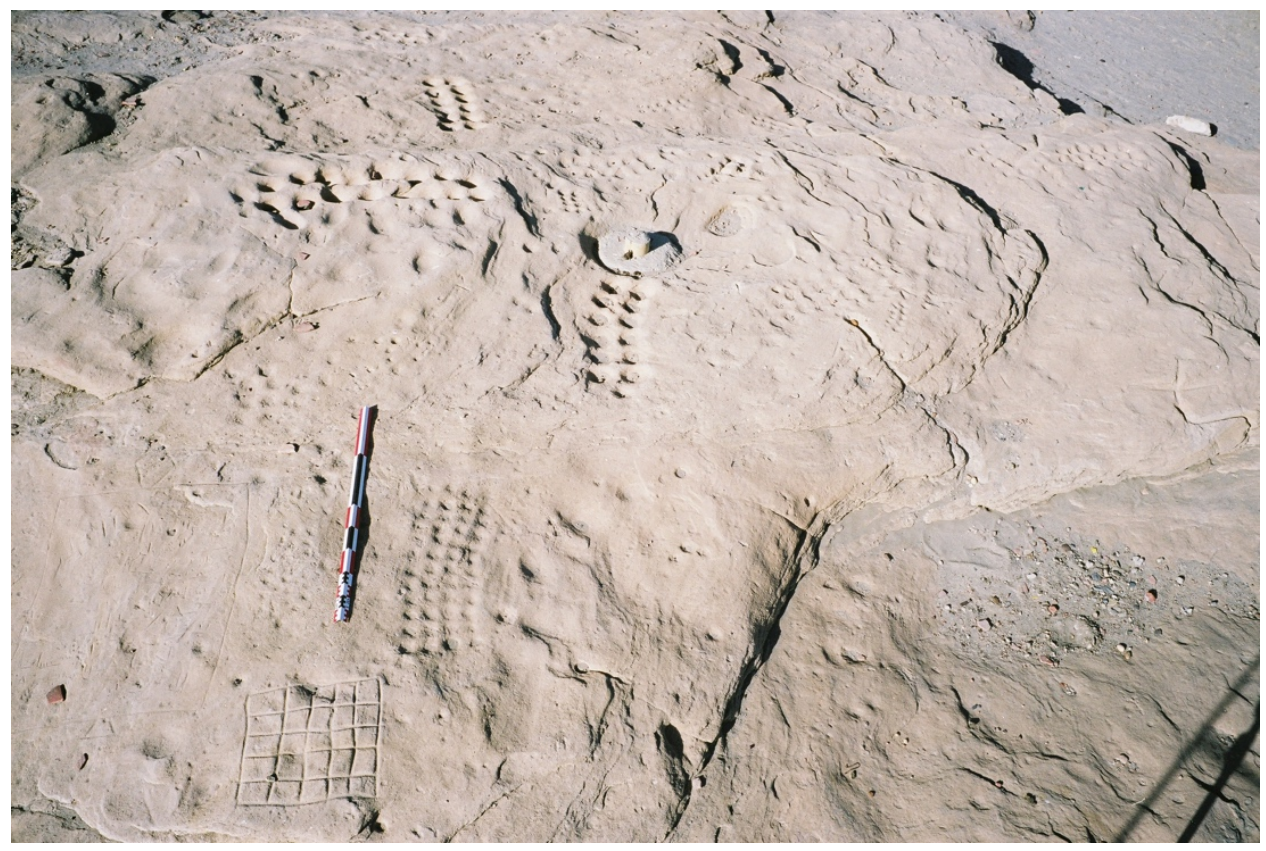

Figure 1: Games context with (from bottom to top) sija, țāb and mancala on Sai Island, Sudan (Photo: Alex de Voogt, 2010) 
boards and even mancala boards, it is based solely on appearance with no additional evidence such as depictions of people playing, other gaming materials or other games. Other games could have provided a games context in which it becomes more likely that the rows of holes are indeed used for gaming. Other contexts, such as the twelfth century anthropomorphic stelae with mancala game designs, as discussed by Joussaume (2011), only provide tangential evidence of earlier mancala game practices. Sufficient supportive material is missing to the extent that we can even doubt that the boards uncovered by Pankhurst and Joussaume are games. While this may seem unreasonably critical of this evidence, the identification of these patterns as mancala game boards remains speculative.

Since Schädler's (1998) study of game boards in Roman Asia Minor, it has become clear that many game boards previously thought to be mancala boards are more likely instances of the game of five lines. Several sites with a Roman presence, including sites in the western part of the empire (see Figure 2.), feature the game of five lines as two rows of five holes, making mancala a second choice at best. In the Near East, the game of $t \bar{a} b$ has been identified at the site of Petra (de Voogt, Hassanat \& Alhasanat 2017), consisting of four rows of holes, similar to four-row mancala games found in East Africa. The game of $t \bar{a} b$ is frequently confused with four-row mancala as archaeologists are rarely familiar with $t \bar{a} b$. Archaeological studies of

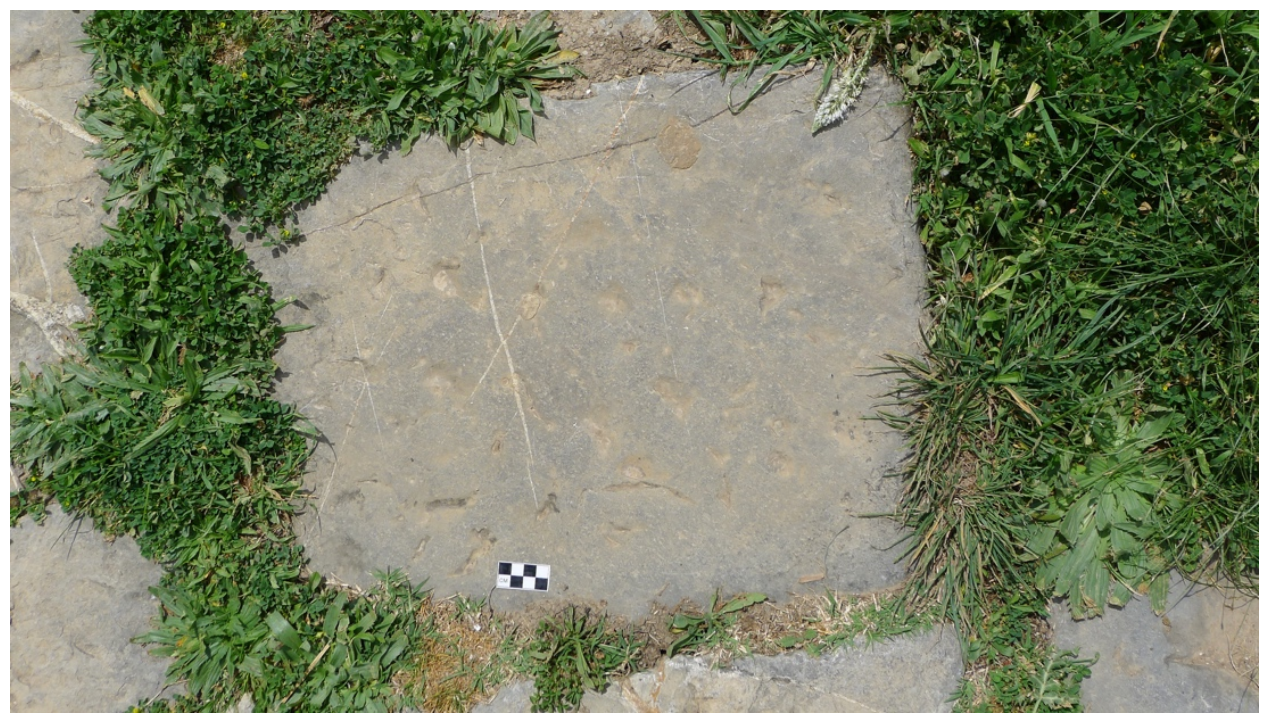

Figure 2: A likely game of five lines at the Roman site of Cuicul (modern Djemila), Algeria. The game is located in the forum, north of the Triumphal Arch (Photo Alex de Voogt, 2011). 
Roman and other sites (e.g., Mulvin \& Sidebotham 2003) continue to confuse rows of holes with mancala. Indeed, Trifilò (2011:322) identified a set of mostly randomly dispersed holes on the Forum Romanum as mancala while they were more likely used for marble lanes (Schädler 2013). In short, the existence of holes should not be equated with the presence of mancala.

In light of the above, and in the absence of corroborating evidence, the rows of holes that might constitute a mancala playing board are rarely sufficient to conclude so. This is particularly frustrating as it would limit evidence for the earliest presence of mancala to literary sources that are explicit about game rules. To this end, Flacourt's (1658; de Voogt 2012) description of a four- row mancala game stands out and gives at least a few hundred years of history to mancala game rules. At the same time, the widespread occurrence of some specific mancala games also allows us to date their introduction. Contact between West Africa and the Caribbean, along the East African Coast, or in South and South-East Asia, as mentioned earlier, has resulted in similar or near-identical games that date to the last known historical contact between the regions. Determining the antiquity of mancala games is probably the most promising when it encompasses a gaming practice - i.e., game boards, game rules, contexts of play and types of players - rather than an isolated game board. In the case of the Maldives, the introduction of the mancala game ohvalhu, which has similar or identical game board variations and game rules in South East Asia, could be dated to the period before the introduction of Islam to the islands, i.e., before 1153 CE (de Voogt 2000).

\section{Egyptian history}

Mancala games were at first considered an African game (Culin 1894), an idea that resonated with several scholars in the twentieth century, associating Africa as the cradle of human evolution and adding Africa as the origin of the first board games. The many sources on Asian mancala games (Deledicq \& Popova 1977, Eagle 1995, de Voogt 1997) has largely dispelled the idea of an African origin. However, the idea of an ancient Egyptian origin has proven more resilient.

Positing an ancient history of specific board games has been common in popular historical works. It was exacerbated by archaeologists who were unfamiliar with board games literature. A Roman latrunculi board in Qasr

Board Game Studies Journal Volume 15, Issue 1, pp. 1-12

DOI: $10.2478 /$ bgs-2021-0001 
Ibrim, Sudan, and ivory squares used for a Roman duodecim scripta board in Sedeinga, Sudan, were originally identified as chess or checkerboards (for a discussion see de Voogt 2015; de Voogt, Francigny \& Baas 2017). In contrast, mancala game boards were sometimes correctly identified but their presence on Egyptian monuments was unjustifiably given as evidence for their Egyptian heritage. These so-called graffiti boards are now better understood (see Crist et al. 2016 for an overview) and both the date of the building and the people who built the monument or structure are usually not associated with the graffiti game board.

The wish to associate certain board games with the ancient Egyptian civilization is more than a misunderstanding of the evidence. It is common to ask what is the oldest game and what is the origin of mancala. The prestige of a game is typically thought to increase if it dates back thousands of years and if it is associated with a particularly illustrious civilization. Even without physical evidence, the idea that mancala games are the oldest games in the world is often suggested or defended.

One possible argument for the antiquity of mancala games is that they are (also) played in the sand. This prevents archaeologists from excavating examples while the simplicity of scooping holes in the ground makes mancala games a likely candidate for the earliest board game. Although it is possible to speculate about such a presence in antiquity, there is sufficient evidence that contradicts this idea. Roman and Greek literature has provided us with overviews of their respective games while ancient Egyptians have left us with several depictions and occasional mentions of board games as well as grave goods and graffiti used for or depicting gaming activity. Neither visual nor literary evidence about mancala games is found in either case while several other games, often and easily scratched on hard surfaces and widely popular, are found both physically and in the literary and art historical evidence. The absence of mancala games in both written sources and in pictorial evidence makes their presence unlikely or at least highly speculative.

\section{Complex society and early states}

Mancala games have often been misidentified and erroneously considered of great antiquity but they are nevertheless important examples

Board Game Studies Journal Volume 15, Issue 1, pp. 1-12 DOI: $10.2478 /$ bgs-2021-0001 
for understanding the connection between states, complex societies and the presence of board games.

In an early anthropological publication, Roberts, Arth and Bush (1959) maintained that "simple societies" should not play strategic games and resist borrowing them. This theory was supported by statistical evidence showing that societies that were defined as lacking complexity were also showing a dearth of strategic games, which by their own definition included all known board games. The statistical evidence was extended by Chick (1998). This theory was first criticized by Townshend (1980) who showed that the thesis was not tenable for pastoral societies playing mancala games but he also suggested that it could still be claimed for so-called hunter- gather societies. The latter groups, more specifically the !Xõo and the Ju|'hoan, also appear to play mancala games and did not resist borrowing them (see Sbrzesny 1976; de Voogt 2017b). A comparison between anthropological descriptions and mancala boards in museum collections (as found in Walker 1990) showed an important bias in the anthropological literature and thereby the dataset used by both Roberts and Chick. Museum game boards sometimes predated the ethnographies that showed no evidence of mancala play in the same society. In the end and based largely on the extensive evidence on mancala games, Chick conceded that the main hypothesis was no longer tenable (Chick 2017; de Voogt 2017a).

This discussion has wider implications that also informs the misguided idea that ancient civilizations and the presence of board games are somehow connected. Mehen, an ancient Egyptian game, is of predynastic origin and already shows the problematic connection between the two. Mancala games in all their complexity have been connected with non-hierarchical communities and societies, dispelling the idea that the complexity of a state is somehow connected to the possibility of conceiving of complex games (de Voogt 2017a). The association of board games in antiquity with the presence of states is at least partially an artifact of archaeology, which has concentrated its excavation efforts on monumental buildings and elite graves. It is, therefore, important to emphasize that even with this bias in archaeology, board games have been found prior to or outside early states, evidence that is most likely underreported.

The above argument seems to support the idea that mancala games may still be the oldest games in the world, since they are games that are not likely to be excavated by archaeologists. This suggestion, however, may be applied

Board Game Studies Journal Volume 15, Issue 1, pp. 1-12 DOI: $10.2478 /$ bgs-2021-0001 
to most board games in antiquity many of which are easily scratched in a surface and played without the presence of a state to warrant their inception.

\section{Ubiquity without antiquity}

The appearance of a mancala board requires as few as two rows of holes, an abstract and relatively simple form that has few if any diagnostic elements. Identifying mancala game boards in the archaeological record requires additional evidence such as other game boards appearing next to supposed mancala boards to create a games context, or, ideally, literary and pictorial evidence.

Despite the limited archaeological evidence of early mancala board games, mancala games consist of a diversity of games each of which has its own history. The possible relationship of all mancala games cannot be determined with the historical evidence of today. Instead, the history of individual mancala games has given evidence about their possible antiquity. Historical contact between regions that explain the distribution of specific mancala gaming practices may point to dates that go back to antiquity. In contrast, the occasional archaeological finds of game boards that resemble a mancala board are rarely accompanied with sufficient corroborating evidence to assume they are mancala games or board games at all.

Mancala games have been instrumental in showing that a connection between the presence of board games and a "complex" society cannot be supported. Similarly, the association of state formation and the inception of board games should also be seen as too speculative. Most mancala games with an especially wide distribution have not been connected with states or supposed complex societies. On the contrary, there is evidence that so-called hunter-gatherer societies, for lack of a better term, developed highly complex gesture games (de Voogt 2017a) and adopted board as well as card games in addition. 


\section{References}

Chick, Garry (1998) "Games in culture revisited: a replication and extension of Roberts, Arth, and Bush (1959)", in Cross-Cultural Research 322:185206.

Chick, Garry (2017) "Comment on 'Strategic games in society: the geography of adult play”" in International fournal of Play 6(3):319-321.

Crist, Walter; Alex de Voogt and Anne-Elizabeth Dunn-Vaturi (2016) "Facilitating interaction: board games as social lubricants in the Ancient Near East", in Oxford Fournal of Archaeology 352:181- 198.

Culin, Stewart (1894) "Mancala, the national game of Africa", in Report of the National Museum, 597-611.

Danilovic, Sandra and Alex de Voogt (2020) "Making sense of abstract board games: toward a cross-ludic theory", in Games $\&$ Culture. DOI: $10.1177 / 1555412020914722$.

Deledicq, Andre and Assia Popova (1977) Wari et Solo: le jeu de calcul Africain. Paris: CEDIC.

de Voogt, Alex (1997) Mancala board games. London: British Museum Press.

de Voogt, Alex (1999) "Distribution of mancala board games: a methodological inquiry", in Board Game Studies 2: 104-114.

de Voogt, Alex (2000) "Mancala rules and cultural changes in Maldivian history", in Fournal of Indian Ocean Studies 7(2\&3): 174-182.

de Voogt, Alex (2012) "Flora, fauna and fifangha: Madagascar by Flacourt", in Tom Baione (ed.), Natural histories: extraordinary rare book selections from the American Museum of Natural History library, pp. 12-15. New York: Sterling Signature.

de Voogt, Alex (2015) "Game boards and game pieces in the Kingdom of Kush: Tokens of cultural contact and influence", in Michael H. Zach 
(ed.), The Kushite World: Proceedings of the $11^{\text {th }}$ International Conference for Meroitic Studies. Beiträge zur Sudanforschung 9:489-495.

de Voogt, Alex (2017a) "Strategic games in society: the geography of adult play", in International Fournal of Play 6(3):308-318.

de Voogt, Alex (2017b) "The absence of games in the presence of claims. Reply to Garry Chick", in International Journal of Play 6(3):322-323.

de Voogt, Alex; Vincent Francigny and Pieter Baas (2017) "Meroitic graves with Roman games: Elites moving the borders of play", in Zeitschrift der Deutschen Morgenlandischen Gesellschaft 167(1):22-33.

de Voogt, Alex; A.B.A. Hassanat and M.B. Alhasanat (2017) "The history and distribution of Țāb: A survey of Petra's gaming boards", in Fournal of Near Eastern Studies 76(1):93-101.

Donkers, Jeroen; Jos Uiterwijk and Alex de Voogt (2002) "Mancala games: Topics in Mathematics and Artificial Intelligence", in Jean Retschitzki \& Rosita Haddad-Zubel (eds.), Step by Step, pp. 133-146. Fribourg: Editions Universitaires.

Eagle, Vernon A. (1995) "On some newly described mancala games from Yunnan Province, China, and the definition of a genus in the family of mancala games", in A.J. de Voogt (ed.) New approaches to board games research: Asian origins and future perspectives, pp. 48-63. Working Papers Series III. Leiden: IIAS.

Flacourt, Etienne de (1658) Histoire de la Grande Isle Madagascar, Paris.

Herskovits, M.J. (1932) "Wari in the New World", in Fournal of the Royal Anthropological Institute 32.

Joussaume, Roger (2011) "Amorigé and the anthropomorphic stelae with compartmented faces of Southern Ethiopia", in Annales d'Ethiopie 26: 105-117.

Board Game Studies Journal Volume 15, Issue 1, pp. 1-12 DOI: $10.2478 /$ bgs-2021-0001 
Lyman, R. L., and Michael J. O’Brien (2003) “Cultural traits: Units of analysis in early twentieth-century anthropology", in Fournal of Anthropological Research 59:225-250.

Mulvin, Lynda and Steven E. Sidebotham (2003) "Roman game boards from Abu Sha'ar (Red Sea Coast, Egypt)", in Antiquity 78:602-617.

Murray, H.J.R. (1952) A history of board games other than chess. Oxford: Oxford at the Clarendon Press.

Roberts, John M; Malcolm J. Arth and Robert R. Bush. (1959) "Games in culture", in American Anthropologist 61(4):597-605.

Pankhurst, Richard (1971) "Gabata and related board games of Ethiopia and the Horn of Africa", in Ethiopia Observer XIV(3):154-206.

Pankhurst, Richard (1982) "Gabata and other board games of Ethiopia and the Horn of Africa", in Azania XVII:27-42.

Sbrzesny, Heide (1976) Die Spiele der !Ko-Buschleute: unter besonderer Berücksichtigung ihrer sozialisierenden und gruppenbindenden Funktionen. München: R. Piper \& Co.

Schädler, Ulrich (1998) "Mancala in Roman Asia Minor”, in Fournal of Board Games Studies 1:10-25.

Schädler, Ulrich (2013) "Jouer aux billes à l'époque romaine", in Archéothéma: Histoire et archéologie 31: 54-55.

Townshend, Philip (1980) "Games of strategy: A new look at correlates and cross-cultural methods", in H. Schwartzman (Ed) Play and Culture: 1978 Proceedings of the Association for the Anthropological Study of Play (pp. 217-225). West Point: Leisure Press.

Townshend, Philip (1986) Games in culture: A contextual analysis of the Swahili board game and its relevance to variation in African mankala. Unpublished Ph.D. Dissertation, Cambridge University. 
Trifilò, Francesco (2011) "Movement, gaming, and the use of space in the Forum", in Ray Laurence \& David J. Newsome (eds.), Rome, Ostia, Pompeii: Movement and Space, pp. 312-331. Oxford: Oxford University Press.

Walker, Roslyn A. (1990) Sculptured mancala game boards. PhD dissertation, Indiana University. 